\title{
New insights into the biological activities of Chrysanthemum morifolium: Natural flavonoids alleviate diabetes by targeting a-glucosidase and the PTP-1B signaling pathway
}

\author{
Mingzhu Chen ${ }^{\text {a }}$, Kaili Wang ${ }^{\text {a }}$, Yinan Zhang ${ }^{a}$, Mengdi Zhang ${ }^{\text {a }}$, Yujiao Ma ${ }^{\text {a }}$, Haifeng Sun ${ }^{\text {a }}$

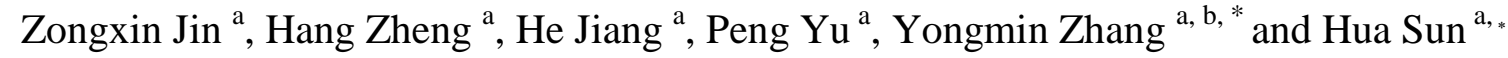 \\ ${ }^{a}$ Key Laboratory of Industrial Fermentation Microbiology of Ministry of Education, China International Science and Technology \\ Cooperation Base of Food Nutrition/Safety and Medicinal Chemistry, Tianjin University of Science and Technology, Tianjin, 300457, China \\ ${ }^{b}$ Sorbonne Université, Institut Parisien de Chimie Moléculaire, UMR CNRS 8232, 4 place Jussieu, 75005 Paris, France
}

\begin{abstract}
As dual regulators, the PTP-1B signaling pathway and $\alpha$-glucosidase slow glucose release and increase the degree of insulin sensitivity, representing a promising therapeutic target for type 2 diabetes. In this study, we systematic examined the in vivo and in vitro anti-diabetic activities of natural flavonoids 1-6 from Chrysanthemum morifolium. Flavonoids 1-6 increased glucose consumption-promoting activity and the phosphorylation of GSK-3 $\beta$ and Akt, and decreased PTP-1B protein level along with slightly inhibitory activity of the PTP1B enzyme. Moreover, flavonoids 1-2 treatment induced insulin secretion in INS-1 cells. Besides, in vivo study revealed that flavonoids $\mathbf{2}$ and $\mathbf{5}$ demonstrated potent anti-hyperglycemic and anti-hyperlipidemic activity, and improved maltose and glucose tolerance. Although flavonoid $\mathbf{2}$ exhibited lower inhibitory activity against $\alpha$-glucosidase in vitro, it could deglycosylated in vivo to diosmetin to function as an $\alpha$-glucosidase inhibitor. Taken together, these results led to the identification of the natural flavonoids 1-6 from $C$. morifolium as dual regulators of $\alpha$-glucosidase and the PTP-1B signaling pathway, suggesting their potential application as new oral anti-diabetic drugs or functional food ingredients.
\end{abstract}

Keywords: Chrysanthemum morifolium; Flavonoid; Diabetes; $\alpha$-Glucosidase; PTP-1B signaling

\section{Introduction}

Chinese "Hangbaiju" comprises the flowering head of Chrysanthemum morifolium, which constitutes an important traditional Chinese medicine used for treatment purposes, e.g., "scattering cold", "cleaning heat and toxins", and "brightening eyes" [1, 2]. C. morifolium has been widely used for approximately 2000 years in China as an herbal tea, and is considered a functional food as it contains many types of biologically active components, such as flavonoids [3-5], triterpenoids [6], and volatile oils [7]. Among these, flavonoids are considered to represent the main bioactive components and have been found to exhibit

* Corresponding authors. Tel.: +86-22-6091-2592; e-mail: sunhua@tust.edu.cn. (Hua Sun); yongmin.zhang@upmc.fr (Yongmin Zhang). 
antioxidant [8,9], cardiovascular-protective [10, 11], and vasorelaxant activities [2, 10]. However, few studies have reported the application of $C$. morifolium as the anti-diabetic functional food and traditional Chinese medicine. The focus of our research is the identification of natural bioactive flavonoids to facilitate their application as functional foods and drug candidates. Our previous studies have identified several series of flavonoids as potent $\alpha$-glucosidase inhibitors [21, 22]. In the present study, we identified two natural flavonoids 1-2 and their aglycone 3, along with flavones 4-6 (Fig. 1B) from C. morifolium and evaluated their in vitro and in vivo anti-diabetic activities.

\section{Materials and methods}

\subsection{Liquid chromatography-mass spectrometry (lc-ms) conditions}

For LC-MS, we utilized a DGU-20A3R high-performance LC instrument coupled to a diode array detector and mass spectrometer (Shimadzu Corporation, LC-MS-IT-TOF, Kyoto, Japan). A $250 \mathrm{~mm} \times 4.6 \mathrm{~mm}, 5-\mu \mathrm{m}$, Symmetry C18 column (Agela Technologies Inc., Torrance, CA) with $20 \mathrm{~mm} \times 3.9 \mathrm{~mm}$ i.d, $5-\mu \mathrm{m}$, sentry guard column was used at a flow rate of $1.0 \mathrm{~mL} / \mathrm{min}$. The column oven temperature was set at $25{ }^{\circ} \mathrm{C}$. The mobile phase consisted of a combination of $\mathrm{A}(0.1 \%$ trifluoroacetic acid in water) and $\mathrm{B}(0.1 \%$ trifluoroacetic acid in acetonitrile). The gradient was varied linearly from $10 \%$ to $26 \%$ B (v/v) in $40 \mathrm{~min}, 65 \%$ B at $70 \mathrm{~min}$, and finally to $100 \% \mathrm{~B}$ at $71 \mathrm{~min}$ and held at $100 \% \mathrm{~B}$ to $75 \mathrm{~min}$. The diode array detection was set at $350,310,270$ and $520 \mathrm{~nm}$ for real-time monitoring of the peak intensity and full spectra (190-650 nm) were continuously recorded for plant component identification. Mass spectra were simultaneously acquired using electrospray ionization in the positive and negative ionization modes at low and high fragmentation voltages $(-3.5$ and $4.5 \mathrm{kV})$ over the range of $\mathrm{m} / \mathrm{z} 100-1,000$.

\subsection{Materials and in vitro protocols}

\subsubsection{Materials}

Dried C. morifolium flower was purchased from Tianfu Tea Co. Ltd. (Zhejiang, China). Baker's yeast $\alpha$-glucosidase, p-nitrophenyl $\alpha$-D-glucopyranoside (pNGP), 4-nitrophenyl phosphate disodium salt (pNPP), $\mathrm{NaVO}_{4}$, acarbose, glibenclamide, and streptozocin (STZ) were purchased from Sigma-Aldrich (St. Louis, MO). Recombinant human PTP1B protein was purchased from Abcam (Cambridge, UK). The BCA Protein Assay Kit was obtained from Beijing Solarbio Science \& Technology Co., Ltd (Beijing, China). PTP-1B antibody, Akt (pan) (11E7) rabbit mAb, phospho-Akt (Ser473) (193H12) rabbit mAb, GSK-3 $\beta$ (D5C5Z) XP rabbit mAb, phospho-GSK-3 $\beta$ (Ser9) (D3A4) rabbit mAb, $\alpha / \beta$-tubulin antibody, and goat anti-rabbit $\operatorname{IgG}(\mathrm{H}+\mathrm{L})$-HRP were purchased from Cell Signaling Technology (Danvers, MA, USA). HepG2 (human liver cancer), CHO-K1 (Chinese hamster ovary), and INS-1 (rat insulin-secreting beta) cells were acquired from Shanghai Institutes for Biological Sciences, Chinese Academy of Sciences (Shanghai, China).

\subsubsection{Glucose consumption $(G C)$ assay}

The GC assay was performed as previously described [22]. Briefly, HepG2 cells were 
cultured in Dulbecco's-modified Eagle's medium (DMEM) containing $25 \mathrm{mM}$ D-glucose, $10 \%$ heat-inactivated fetal bovine serum (FBS), $10 \mathrm{U} / \mathrm{mL}$ penicillin, and $10 \mathrm{mg} / \mathrm{mL}$ streptomycin at $37{ }^{\circ} \mathrm{C}$ under a $5 \% \mathrm{CO}_{2}$ atmosphere. Cells were deprived of serum for $24 \mathrm{~h}$. The cells were washed twice with phosphate buffered saline (PBS), and the medium was replaced by RPMI-1640 containing glucose $(11.1 \mathrm{mM})$ supplemented with $0.2 \%$ bovine serum albumin. Then, metformin $(0.5 \mathrm{mM})$ or test flavonoids were added to the medium at different concentrations. Dimethyl sulfoxide (DMSO) was used as the blank control. The glucose concentration in the medium was determined via the glucose oxidase method after $24 \mathrm{~h}$ treatment.

\subsubsection{MTT method}

The MTT assay was performed before the GC experiment. MTT $(20 \mu \mathrm{L}, 5 \mathrm{mg} / \mathrm{mL}$ dissolved in PBS) was added to each well. After $4 \mathrm{~h}$, DMSO $(100 \mu \mathrm{L})$ was added to dissolve the crystals, and the plate was placed on a shaker for $10 \mathrm{~min}$. The OD value was measured using a microplate reader at a wavelength of $492 \mathrm{~nm}$. The MTT results were used to normalize the GC results. GC owing to cell proliferation can be deducted by calculating the ratio of the $\mathrm{GC}$ and $\mathrm{MTT}(\mathrm{GC} / \mathrm{MTT}=\mathrm{mM} / \mathrm{OD})$.

\subsubsection{Western blotting}

CHO-K1 cells were cultured in DMEM/F-12 Ham's medium supplemented with $10 \%$ FBS, penicillin $(50 \mathrm{U} / \mathrm{mL})$, and streptomycin $(100 \mu \mathrm{g} / \mathrm{mL})$ at $37{ }^{\circ} \mathrm{C}$ in a humidified atmosphere with $5 \% \mathrm{CO}_{2}$ [23]. Cells $\left(5 \times 10^{4} / \mathrm{mL}\right)$ were seeded in a 96 -well cell plate for $24 \mathrm{~h}$ and then treated with compounds 1-6 $(20 \mu \mathrm{M})$ or DMSO for $48 \mathrm{~h}$. $\mathrm{NaVO}_{4}$ was used as a positive control. Then, the cells were lysed with ice-cold RIPA buffer containing freshly added aprotinin and phenylmethanesulfonyl fluoride. The BCA Protein Assay Kit was used to determine protein concentration. Cell lysates were separated by sodium dodecyl sulfate-polyacrylamide gel electrophoresis and then transferred onto a polyvinylidene fluoride membrane (Millipore, Billerica, MA). The membranes were blocked with 5\% non-fat milk in $1 \times$ PBS containing $0.5 \%$ Tween 20 (PBST) for $1 \mathrm{~h}$ at room temperature and were then incubated with a primary antibody overnight at $4{ }^{\circ} \mathrm{C}$. The following day, the membranes were washed three times with PBST and probed with a secondary antibody. Pierce $^{\mathrm{TM}}$ ECL Western Blotting Substrate (Thermo Scientific, Waltham, MA) was used to detect the bands [24].

\subsubsection{Glucose-stimulated insulin secretion and basal insulin secretion}

INS-1 cells were cultured in Iscove's modified Dulbecco's medium (IMDM) supplemented with $10 \% \mathrm{FBS}$, streptomycin $(100 \mu \mathrm{g} / \mathrm{mL})$, and penicillin $(50 \mathrm{U} / \mathrm{mL})$ at $37{ }^{\circ} \mathrm{C}$ in a humidified atmosphere containing $5 \% \mathrm{CO}_{2}$. Cells $\left(2 \times 10^{5}\right.$ cells $\left./ \mathrm{mL}\right)$ were seeded in a 48 -well cell plate for $24 \mathrm{~h}$. The cell culture medium was replaced by IMDM containing $40 \mathrm{mM}$ glucose then cells were incubated with compounds or DMSO for $48 \mathrm{~h}$. Glibenclamide was used as a positive control. Thereafter, the cell culture medium was carefully removed, the cells were washed with PBS, and $300 \mu \mathrm{L}$ Krebs-Ringer's bicarbonate (KRB) buffer containing $2 \%$ FBS was added. After $30 \mathrm{~min}$, the cells were stimulated with KRB buffer containing 5 or $30 \mathrm{mM}$ (BIS or GSIS) glucose for $60 \mathrm{~min}$ at $37^{\circ} \mathrm{C}$. The cell medium was then collected for analysis of insulin secretion, which was determined using a rat insulin enzyme-linked immunosorbent 
assay kit (Nanjingjiancheng, Nanjing, China), whereas $100 \mu \mathrm{L}$ RIPA Lysis buffer was added to the cells, which were saved for determination of the total protein content [25].

\subsubsection{Inhibition studies of $P T P-1 B$}

pNPP was used as a substrate for the measurement of PTP1B activity. Compounds 1-6 were dissolved in DMSO. PTP-1B, pNPP, and $\mathrm{NaVO}_{4}$ were dissolved in assay buffer $(\mathrm{pH}$ 6.0), which contains $150 \mathrm{mM} \mathrm{NaCl}, 50 \mathrm{mM}$ 2-(N-morpholino) ethanesulfonic acid, $1 \mathrm{mM}$ ethylenediaminetetraacetic acid, $1 \mathrm{mM}$ dithiothreitol, and $0.05 \%$ NP-40. Enzymatic reaction mixtures, composed of PTP-1B $(20 \mu \mathrm{g} / \mathrm{mL}, 5 \mu \mathrm{L})$, test compounds $(10 \mu \mathrm{L})$, and buffer $(75$ $\mu \mathrm{L})$, were incubated at $30{ }^{\circ} \mathrm{C}$ for $5 \mathrm{~min}$, then the reactions were initiated by adding pNPP $(100 \mathrm{mM}, 10 \mu \mathrm{L})$ and incubated at $30{ }^{\circ} \mathrm{C}$ for $10 \mathrm{~min}$. Enzymatic activity was detected by spectrophotometry at $405 \mathrm{~nm}$ [27].

\subsubsection{Inhibition studies of $\alpha$-glucosidase}

Test compounds 1-6 and acarbose were dissolved in DMSO. $\alpha$-Glucosidase and pNGP were dissolved in potassium phosphate buffer $(0.05 \mathrm{M}, \mathrm{pH}$ 6.8). Enzymatic reaction mixtures, composed of $\alpha$-glucosidase ( $4 \mathrm{mU}, 20 \mu \mathrm{L})$, pNGP $(75 \mu \mathrm{M}, 30 \mu \mathrm{L})$, test compounds $(10 \mu \mathrm{L})$, and potassium phosphate buffer $(140 \mu \mathrm{L})$, were incubated at $37^{\circ} \mathrm{C}$ for $30 \mathrm{~min}$. Enzymatic activity was detected by spectrophotometry at $405 \mathrm{~nm}$.

\subsection{Materials and in vivo protocols}

\subsubsection{Animals and diets}

Four- to six-week-old male Kunming mice (18-22 g) were procured from The Institute for Laboratory Animal Science, Chinese Academy of Medical Sciences and Peking Union Medical College [Beijing, China, License SCXK (Jun) 2012-0004]. Animal procedures were approved by the Tianjin University of Science and Technology Institutional Animal Care Committee and performed in strict compliance with local and national ethical guidelines. The mice were kept in polypropylene cages (five in each cage) and housed under laboratory conditions $\left(18-23{ }^{\circ} \mathrm{C}\right.$, 55-60\% humidity, $12 \mathrm{~h}$ light/dark cycle). The mice were fed a standard pellet diet for 1 week after arrival and randomly divided into two groups: mice fed a standard pellet diet (normal mice), and mice fed a high-fat, high-fructose diet to induce type 2 diabetes. All mice had free access to food and water [21].

\subsubsection{Induction of experimental type 2 diabetic mice and treatment}

After ingesting the high-fat, high-fructose food for 3 weeks, the mice were subjected to a $12 \mathrm{~h}$ fast. Type 2 diabetes was induced by an intraperitoneal injection of STZ [100 mg/kg of body weight, dissolved in $0.05 \mathrm{M}$ citrate buffer ( $\mathrm{pH} 4.5$ )]. After another 2 weeks of the high-fat, high-fructose diet, fasting blood from the tail vein was used to determine blood GC. The mice were classified as having type 2 diabetes if blood glucose levels were $>11.0 \mathrm{mM}$. Type 2 diabetic mice were fed the high-fat, high-fructose diet throughout the study. Blood glucose and body weight were checked every week. Type 2 diabetic mice were divided into 6 groups with 10 mice per group. Each day, $10 \mathrm{~mL}$ of saline/kg, $50 \mathrm{mg}$ of acarbose in saline $/ \mathrm{kg}$, 50 and $100 \mathrm{mg}$ of diosmin in saline $/ \mathrm{kg}$, and 50 and $100 \mathrm{mg}$ of apigenin in saline/kg were 
orally administered to groups 1 (T2D model), 2 (acarbose), 3 (diosmin, $50 \mathrm{mg} / \mathrm{kg}$ ), 4 (diosmin, $100 \mathrm{mg} / \mathrm{kg}$ ), 5 (apigenin, $50 \mathrm{mg} / \mathrm{kg}$ ), and 6 (apigenin, $100 \mathrm{mg} / \mathrm{kg}$ ), respectively.

\subsubsection{Determination of blood glucose levels}

Blood glucose levels were determined as previously described [28]. After receiving treatment for 13 and 14 days and fasting overnight, all mice were orally administered glucose or maltose $(2 \mathrm{~g} / \mathrm{kg})$, respectively, $60 \mathrm{~min}$ after treatment. Blood samples were taken from the tail vein after $0,30,60$, and $120 \mathrm{~min}$, and blood glucose was measured using a glucometer (Sinocare, Changsha, China). Areas under the curve (AUCs) were calculated using the trapezoidal rule.

\subsubsection{Determination of blood lipid levels}

Blood lipid levels were determined as previously described [29]. At the end of the experimental period, blood samples were collected and the serum samples obtained by centrifugation (2000 $\mathrm{g}$ for $20 \mathrm{~min}$ ) were stored at $-20^{\circ} \mathrm{C}$ for further analysis. Serum total cholesterol (TC) and triglycerides (TGs) were analyzed using commercial diagnostic kits (Jiancheng, Nanjing, China).

\section{Results and discussion}

\subsection{Identification of C. morifolium flavonoids}

In order to gain some anti-diabetic insight into the flavonoids of $C$. morifolium, the flavonoids were purified and identified purposely. Dried C. morifolium flower was finely powdered. The sample $(60 \mathrm{~g})$ was refluxed and extracted with ethanol-water $(480 \mathrm{~mL}, 75: 25$, $\mathrm{v} / \mathrm{v})$ using a Soxhlet extractor 3 times for $1 \mathrm{~h}$. The extract was combined and lyophilized to give crude powder $(15.64 \mathrm{~g})$, of which $15 \mathrm{mg}$ was dissolved in methanol $(1 \mathrm{~mL})$ and filtered through a $0.22 \mu \mathrm{m}$ nylon filter. Filtered sample $(20 \mu \mathrm{L})$ was injected for analysis. Chromatograms of the C. morifolium extract are shown in Fig. 1A. The retention times $\left(\mathrm{t}_{\mathrm{R}}\right)$, molecular ions $\left(\left[\mathrm{M}+\mathrm{Na}^{+} /[\mathrm{M}-\mathrm{H}]^{-}\right)\right.$, and major fragment ions of the major peaks are listed in Table 1. Flavonoids in C. morifolium flower were identified based on a comparison of retention times and high-resolution mass spectra for authentic standards obtained using the same reported methods [1]. As shown in figure 1, two flavonoids 1-2 and flavones 3-6 in the aqueous ethanol extract of C. morifolium were identified as diosmetin 7-glucoside (1, peak 1), diosmin (2, peak 2), diosmetin (3, peak 3), luteolin (4, peak 4), apigenin (5, peak 5), and acacetin (6, peak 6). The assignment of nuclear magnetic resonance and mass spectrometry spectra is described in the supporting information.

(Figure 1)

\subsection{Promotion of GC by flavonoids 1-6 in HepG2 cells}

To assess the anti-diabetic activity of flavonoids 1-6 in C. morifolium flower, the GC in HepG2 cells was evaluated. The GC results were normalized using their MTT results. As shown in Fig. 2A, all flavonoids 1-6 significantly promote glucose-consumption at doses of 0.4-10 $\mu \mathrm{M}$. Of these, flavone $\mathbf{4}$ was found to have the highest activity, being similar potent at dose of $4 \mu \mathrm{M}$ with metformine at dose of $500 \mu \mathrm{M}$. Besides, Flavonoid 2 was slightly more 
potent than $\mathbf{1}$.

(Figure 2)

\subsection{Enhanced insulin signaling by flavonoids 1-6}

Insulin signaling is dependent on activation of the insulin receptor, which phosphorylates and recruits different downstream signaling molecules. Thus, phosphorylation of the signaling molecules serves as an indicator of pathway activation. Insulin-stimulated phosphorylation of GSK-3 $\beta$ (Ser9) was significantly increased by flavonoids 1-6 treatment in the cell cultures (Fig. 3A and B). Phosphorylation of Akt (Ser473) was also obviously enhanced (Fig. 3A and C). Moreover, the protein levels of PTP-1B were evidently decreased by 1-6 (Fig. 3A and D). To further determine the effect on PTP-1B, the inhibitory activity of hPTP-1B was performed. The results showed that flavonoids 1-6 exhibited weak inhibitory activity against $\mathrm{hPTP}-1 \mathrm{~B}$ at 1,5 , and $20 \mu \mathrm{M}$ (Table 2). These results suggested that flavonoids 1-6 directly enhanced the insulin signaling activity and decreased the protein level of PTP-1B along with slightly inhibiting the activity of the PTP1B enzyme.

(Figure 3)

(Table 2)

\subsection{Effects of flavonoids 1-2 on insulin secretion in high glucose-treated INS-1 cells}

To further determine the effect of insulin signaling pathway by representative flavonoids 1-2, we performed an insulin secretion test in the high glucose-treated INS-1 cellular model. Glibenclamide used as a positive control. As shown in Fig. 2B and C, after treatment with 30 and $5.5 \mathrm{mM}$ glucose, insulin secretion of cells significantly decreased (normal vs. high glucose-treated model). Treatment with $0.1,1,10$, and $100 \mu \mathrm{M}$ flavonoids 1 and 2 increased dose-dependently the level of insulin secretion, which previously decreased by glucose in both groups. These results suggested that flavonoids 1-2 treatment induced insulin secretion in INS-1 cells.

\section{5. $\alpha$-Glucosidase inhibition of C. morifolium flavonoids}

To discover the targets of anti-diabetic, $\alpha$-glucosidase inhibitory activity of flavonoids 1-6 was investigated. Acarbose, a clinical $\alpha$-glucosidase inhibitor, was selected as a reference compound. As shown in Table 3, flavone $5\left(\mathrm{IC}_{50}=9.04 \mu \mathrm{M}\right)$ was found to have the highest activity, being even more active than acarbose $\left(\mathrm{IC}_{50}=236.5 \mu \mathrm{M}\right)$. Moreover, no apparent inhibitory activity against $\alpha$-glucosidase was observed for flavonoids $\mathbf{1}$ and $\mathbf{2}$, with $\mathrm{IC}_{50}$ values $>100$. However, diosmetin, the aglycone (3) of flavonoids $\mathbf{1}$ and $\mathbf{2}$, exhibited comparable $\alpha$-glucosidase inhibitory activity with acarbose. As it has been reported that deglycosylation of flavonoids constitutes a major metabolic pathway for these compounds [30, 31]. We considered that although flavonoids $\mathbf{1}$ and $\mathbf{2}$ exhibit no $\alpha$-glucosidase inhibitory activity in vitro, they might be deglycosylated to diosmetin in vivo, which is positive for anti-diabetic activity.

\subsection{Flavonoids ameliorates hyperglycemia in vivo}

To further evaluate the in vivo anti-diabetic activity and validate our hypotheses of deglycosylation, the hypoglycemic activity of representative flavonoid $\mathbf{2}$ and $\mathbf{5}$ was 
determined using STZ-induced diabetic mice. Compared with normal mice (health group), diabetic mice (T2D model group) exhibited hyperglycemia with blood glucose levels of approximately $23 \mathrm{mM}$ (Fig. 4A). After 4-week treatment with flavonoids 2 and 5, blood glucose levels significantly decreased compared with those of the vehicle group (Fig. 4A and B).

(Figure 4)

\subsection{Flavonoids improves maltose and glucose tolerance in vivo}

To assess glucose homeostasis and insulin sensitivity in diabetic mice treated with flavonoid $\mathbf{2}$ and $\mathbf{5}$, we evaluated the amelioration of glucose tolerance. Flavonoids $\mathbf{2}$ and $\mathbf{5}$ administration resulted in a significant improvement in glucose tolerance (Fig. 4C and D). To understand the basis of flavonoid $\mathbf{2}$ and $\mathbf{5}$ activity with regard to $\alpha$-glucosidase suppression, we further investigated the influence of flavonoid $\mathbf{2}$ and $\mathbf{5}$ on blood glucose levels using an in vivo maltose tolerance test. Blood glucose levels after oral administration of maltose indirectly reflect the activity of $\alpha$-glucosidase, which can hydrolyze maltose into glucose. As shown in Fig. 4E, after treatment with flavonoid 2 and 5 for 2 h, postprandial blood glucose level obviously improved compared with that of the diabetic model group. AUCs of flavonoid 2 were reduced by $11.2 \%$ and $13.5 \%$ at a dosage of 50 and $100 \mathrm{mg} / \mathrm{kg}$, respectively (Fig. 4F). Thus, despite the lack of in vitro inhibitory activity against $\alpha$-glucosidase, flavonoid 2 appeared capable of significant decreasing fasting blood glucose levels and improving maltose and glucose tolerance in vivo. Consequently, flavonoid 2 exhibited comparable in vivo anti-diabetic activity with acarbose. The results strongly supported our conjecture that flavonoid 2 might be deglycosylated in vivo to diosmetin to function as an $\alpha$-glucosidase inhibitor.

\subsection{Flavonoids reduces serum levels of $T G$ and $T C$}

After 4 weeks of treatment with flavonoid $\mathbf{2}$ and $\mathbf{5}$, a significant decrease in serum levels of TG and TC was observed (Table 4). TG levels were decreased by $33.8 \%(50 \mathrm{mg} / \mathrm{kg}$ ) and $27.3 \%$ $(100 \mathrm{mg} / \mathrm{kg})$ for flavonoid 2 , whereas TC levels were decreased by $8.3 \%(100 \mathrm{mg} / \mathrm{kg})$ compared to those of diabetic model mice. Especially, TC levels were decreased by $22.1 \%$ $(50 \mathrm{mg} / \mathrm{kg}$ ) and $15.7 \%(100 \mathrm{mg} / \mathrm{kg})$ for flavonoid 5 compared to those of diabetic model mice. However, acarbose at a dosage of $50 \mathrm{mg} / \mathrm{kg}$ exhibited no anti- hyperlipidemia activity.

(Table 4)

\section{Conclusion}

The PTP-1B signaling pathway plays an important in the regulation of insulin signaling and the development of type 2 diabetes and obesity. $\alpha$-Glucosidase catalyzes the final step of carbohydrate digestion and releases glucose. As dual regulators, the PTP-1B signaling pathway and $\alpha$-glucosidase slow the release of glucose and increase the degree of insulin sensitivity, resulting in alleviation of disorders of glucose and lipid metabolism and insulin resistance, thereby representing a promising potential therapeutic strategy for the treatment of type 2 diabetes. To identify natural compounds that may influence this process, we performed in vitro cell-based and enzyme-based experiments to determine the effect on proteins related to the PTP-1B signaling pathway and $\alpha$-glucosidase. The results showed that flavonoids 1-6 
significantly promote glucose consumption (Fig. 2A). The phosphorylation of GSK-3 $\beta$ and Akt was increased and the protein level of PTP1B was decreased by flavonoid 1-6 treatment (Fig. 3). However, flavonoids 1-6 showed only weak inhibitory activity against PTP-1B at 1, 5, and $20 \mu \mathrm{M}$ (Table 2). Moreover, flavonoids 1-2 were capable of increasing insulin secretion in INS-1 cells (Fig. 2B and C).

Given that the in vitro potencies of many PTP-1B regulators or $\alpha$-glucosidase inhibitors are not consistent with their in vivo activities, a series of in vivo anti-diabetic activities were evaluated in STZ-induced type 2 diabetic mice. Moreover, as the oral availability of PTP-1B represents a challenge for the development of PTP-1B inhibitors [24], we examined the effects of 4-week oral administration of flavonoid $\mathbf{2}$ and $\mathbf{5}$ in diabetic mice. Flavonoid $\mathbf{2}$ administration resulted in a significant reduction in fasting blood glucose levels (Fig. 4A and B) combined with a significant improvement in glucose tolerance (Fig. 4C and D). Furthermore, flavonoid $\mathbf{2}$ and $\mathbf{5}$ ameliorated maltose tolerance comparing with that in the diabetic model group (Fig. 4E and F), which indirectly reflected the in vivo activity of $\alpha$-glucosidase.

Dyslipidemia, characterized by hypertriglyceridemia including TG and TC levels, constitutes a major risk factor contributing to the burden of macrovascular disease in type 2 diabetes. In the present study, flavonoid $\mathbf{2}$ and $\mathbf{5}$ showed potent lipid lowering capability in the diabetic mice, eliciting reduced serum TC and TG levels (Table 4). It is considered that the alleviation of insulin resistance may have contributed to the lower TC and TG levels.

In conclusion, natural flavonoids 1-6 from $C$. morifolium were identified as $\alpha$-glucosidase and PTP-1B signaling pathway dual regulators, which could serve as a new starting point for the discovery of novel oral anti-diabetic agents and potential functional food ingredients.

\section{Conflict of interest statement}

The authors declare no conflicts of interest.

\section{Ethics statement}

I have read and adhere to the Publishing Ethics.

\section{Acknowledgements}

This work was supported by the National Natural Science Foundation of China (21502138) and Natural Science Foundation of Tianjin (18JCYBJC94800).

\section{Supporting information}

Supplementary data related to this article can be found at http://.

These data include NMR and mass spectra signals of compounds 1-6 described in this article.

\section{References}

[1] L.-Z. Lin, J.M. Harnly, Identification of the phenolic components of chrysanthemum flower (Chrysanthemum morifolium Ramat), Food Chemistry, 120 (2010) 319-326.

[2] S. Wang, L.J. Hao, J.J. Zhu, Q.W. Zhang, Z.M. Wang, X. Zhang, X.M. Song, Study on the effects of sulfur fumigation on chemical constituents and antioxidant activity of Chrysanthemum morifolium cv. Hang-ju, 
Phytomedicine, 21 (2014) 773-779.

[3] C.W. Beninger, M.M. Abou-Zaid, A.L.E. Kistner, R.H. Hallett, M.J. Iqbal, B. Grodzinski, J.C. Hall, A flavanone and two phenolic acids from Chrysanthemum morifolium with phytotoxic and insect growth regulating activity, J Chem Ecol, 30 (2004) 589-606.

[4] T. Chen, L.P. Li, X.Y. Lu, H.D. Jiang, S. Zeng, Absorption and excretion of luteolin and apigenin in rats after oral administration of Chrysanthemum morifolium extract, Journal of agricultural and food chemistry, 55 (2007) 273-277.

[5] Q.S. Guo, T. Wang, L.T. Cheng, J.J. Wen, T.Y. Wang, Y.N. Liang, [Study on quality of flavone in various cultivars of Chrysanthemum morifolium for medicine], Zhongguo Zhong yao za zhi = Zhongguo zhongyao zazhi = China journal of Chinese materia medica, 33 (2008) 756-759, 779.

[6] T. Akihisa, S.G. Franzblau, M. Ukiya, H. Okuda, F. Zhang, K. Yasukawa, T. Suzuki, Y. Kimura, Antitubercular activity of triterpenoids from Asteraceae flowers, Biol Pharm Bull, 28 (2005) 158-160.

[7] L. Yang, P. Cheng, J.H. Wang, H. Li, Analysis of Floral Volatile Components and Antioxidant Activity of Different Varieties of Chrysanthemum morifolium, Molecules, 22 (2017).

[8] P.H. Zhang, H.Q. Tang, M.Z. Zheng, Y.Y. Chen, Y.L. Shen, [Effect of total flavonoids from Chrysanthemun morifolium on learning and memory in aging mice], Zhongguo ying yong sheng li xue za zhi = Zhongguo yingyong shenglixue zazhi = Chinese journal of applied physiology, 27 (2011) 368-371.

[9] Q. Wei, X.Y. Ji, X.S. Long, Q.R. Li, H. Yin, [Chemical Constituents from Leaves of "Chuju" Chrysanthemum morifolium and Their Antioxidant Activities in vitro], Zhong yao cai $=$ Zhongyaocai $=$ Journal of Chinese medicinal materials, 38 (2015) 305-310.

[10] H.F. Jin, X.W. Liu, Y.M. Tang, L.J. Tang, Y.L. Wang, C.Q. Du, Effects of total flavones from Dendranthema morifolium on vasocontraction and proliferation of vascular smooth muscle cells, Molecular medicine reports, 13 (2016) 989-993.

[11] C.K. Lii, Y.P. Lei, H.T. Yao, Y.S. Hsieh, C.W. Tsai, K.L. Liu, H.W. Chen, Chrysanthemum morifolium Ramat. reduces the oxidized LDL-induced expression of intercellular adhesion molecule-1 and E-selectin in human umbilical vein endothelial cells, J Ethnopharmacol, 128 (2010) 213-220.

[12] W.S.K. Lee, Hye Jeong; Shin, Seong Cheol, Composition comprising polyphenol isolated from Artemisia annua as active ingredient for preventing or treating cancer, in, 2017.

[13] P. Hu, D.H. Li, C.C. Jia, Q. Liu, X.F. Wang, Z.L. Li, H.M. Hua, Bioactive constituents from Vitex negundo var. heterophylla and their antioxidant and alpha-glucosidase inhibitory activities, J Funct Foods, 35 (2017) 236-244.

[14] W.Y. Liu, S.-S. Liou, T.-Y. Hong, I.M. Liu, The benefits of the citrus flavonoid diosmin on human retinal pigment epithelial cells under high-glucose conditions, Molecules, 22 (2017) 2251/2251-2251/2212.

[15] R. El-Fawal, H.M. El Fayoumi, M.F. Mahmoud, Diosmin and crocin alleviate nephropathy in metabolic syndrome rat model: Effect on oxidative stress and low grade inflammation, Biomed Pharmacother, 102 (2018) 930-937.

[16] M. Anwar, W.G. Shousha, H.A. El-Mezayen, R. Awadallah, M. El-Wassef, N.M. Nazif, M.A. El-Bana, Almond oil and extracted diosmin as prophylaxis for the endothelial dysfunction in diabetic rats, J. Chem. Pharm. Res., 6 (2014) 184-194, $111 \mathrm{pp}$.

[17] C.C. Hsu, M.H. Lin, J.T. Cheng, M.C. Wu, Antihyperglycaemic action of diosmin, a citrus flavonoid, is induced through endogenous -endorphin in type I-like diabetic rats, Clin Exp Pharmacol P, 44 (2017) 549-555.

[18] W.C. Ko, C.M. Shih, Y.H. Lai, J.H. Chen, H.L. Huang, Inhibitory effects of flavonoids on phosphodiesterase isozymes from guinea pig and their structure-activity relationships, Biochemical pharmacology, 68 (2004) 2087-2094. 
[19] T.S. Park, Composition for preventing or treating muscle diseases, containing, as active ingredient, diosmin or pharmaceutically acceptable salt thereof, in, Industry-Academic Cooperation Foundation, Yonsei University, S. Korea . 2018, pp. 42pp.

[20] A.M. Browning, U.K. Walle, T. Walle, Flavonoid glycosides inhibit oral cancer cell proliferation--role of cellular uptake and hydrolysis to the aglycones, The Journal of pharmacy and pharmacology, 57 (2005) 1037-1042.

[21] H. Sun, D. Wang, X. Song, Y. Zhang, W. Ding, X. Peng, X. Zhang, Y. Li, Y. Ma, R. Wang, P. Yu, Natural Prenylchalconaringenins and Prenylnaringenins as Antidiabetic Agents: alpha-Glucosidase and alpha-Amylase Inhibition and in Vivo Antihyperglycemic and Antihyperlipidemic Effects, Journal of agricultural and food chemistry, 65 (2017) 1574-1581.

[22] H. Sun, W.N. Ding, X.T. Song, D. Wang, M.Z. Chen, K.L. Wang, Y.Z. Zhang, P. Yuan, Y. Ma, R.L. Wang, R.H. Dodd, Y.M. Zhang, K. Lu, P. Yu, Synthesis of 6-hydroxyaurone analogues and evaluation of their alpha-glucosidase inhibitory and glucose consumption-promoting activity: Development of highly active 5,6-disubstituted derivatives, Bioorganic \& Medicinal Chemistry Letters, 27 (2017) 3226-3230.

[23] D. Ye, Y. Zhang, F. Wang, M. Zheng, X. Zhang, X. Luo, X. Shen, H. Jiang, H. Liu, Novel thiophene derivatives as PTP1B inhibitors with selectivity and cellular activity, Bioorg Med Chem, 18 (2010) 1773-1782.

[24] J. Luo, Q. Xu, B. Jiang, R. Zhang, X. Jia, X. Li, L. Wang, C. Guo, N. Wu, D. Shi, Selectivity, cell permeability and oral availability studies of novel bromophenol derivative HPN as protein tyrosine phosphatase $1 \mathrm{~B}$ inhibitor, $\mathrm{Br} \mathrm{J}$ Pharmacol, 175 (2018) 140-153.

[25] H.-A. Lee, J.-H. Lee, J.-S. Han, 2,7"-Phloroglucinol-6,6'-bieckol protects INS-1 cells against high glucose-induced apoptosis, Biomed Pharmacother, 103 (2018) 1473-1481.

[26] Y. Saidu, S.A. Muhammad, A.Y. Abbas, A. Onu, I.M. Tsado, L. Muhammad, In vitro screening for protein tyrosine phosphatase $1 \mathrm{~B}$ and dipeptidyl peptidase IV inhibitors from selected Nigerian medicinal plants, Journal of Intercultural Ethnopharmacology, 6 (2016) 154.

[27] X. Zhang, J. Tian, J. Li, L. Huang, S. Wu, W. Liang, L. Zhong, J. Ye, F. Ye, A novel protein tyrosine phosphatase 1B inhibitor with therapeutic potential for insulin resistance, Br J Pharmacol, 173 (2016) 1939-1949.

[28] S.H. Lee, M.H. Park, S.J. Heo, S.M. Kang, S.C. Ko, J.S. Han, Y.J. Jeon, Dieckol isolated from Ecklonia cava inhibits alpha-glucosidase and alpha-amylase in vitro and alleviates postprandial hyperglycemia in streptozotocin-induced diabetic mice, Food Chem Toxicol, 48 (2010) 2633-2637.

[29] L.S. Wan, C.P. Chen, Z.Q. Xiao, Y.L. Wang, Q.X. Min, Y. Yue, J. Chen, In vitro and in vivo anti-diabetic activity of Swertia kouitchensis extract, J Ethnopharmacol, 147 (2013) 622-630.

[30] J. Xu, D.W. Qian, S. Jiang, J.M. Guo, E.X. Shang, J.A. Duan, J. Yang, UPLC-Q-TOF/MS for Analysis of the Metabolites of Flavone Glycosides from Scutellaria baicalensis Georgi by Human Fecal Flora in Vitro, Chromatographia, 76 (2013) 975-983.

[31] B. Guo, X.R. Fan, Z.Z. Fang, Y.F. Cao, C.M. Hu, J.L. Yang, Y.Y. Zhang, R.R. He, X. Zhu, Z.W. Yu, X.Y. Sun, M. Hong, L. Yang, Deglycosylation of Liquiritin Strongly Enhances its Inhibitory Potential Towards UDP-Glucuronosyltransferase (UGT) Isoforms, Phytotherapy Research, 27 (2013) 1232-1236. 


\section{$393 \quad$ Figure legends}

394 Fig. 1. Chromatograms of the aqueous ethanol extract and structures of natural flavonoids 1-6 of C. morifolium.

395 (A) Chromatograms $(350 \mathrm{~nm})$ of the aqueous ethanol extract. Chromatograms of the C. morifolium extract (a), 396 diosmetin 7-glucoside (b), diosmin (c), diosmetin (d), luteolin (e), apigenin (f), and acacetin (g). (B) Structures 397 of identified flavonoids 1-6 from C. morifolium.

398 Fig. 2. Effects of flavonoids 1-6 on promote glucose consumption (GC) and flavonoids 1-2 on insulin secretion. 399 (A) Flavonoids 1-6 promote GC in HepG2 cells. Metformin (Met) was used as a reference compound. ${ }^{*} P<0.05$, $400 \quad{ }^{* *} P<0.01$, and ${ }^{* * *} P<0.001$ vs control. Effects of flavonoids $1-2$ on insulin secretion in high glucose-treated 401 INS-1 cells. INS-1 cells were preincubated with $40 \mathrm{mM}$ glucose and compounds or DMSO for $48 \mathrm{~h}$. Cells were 402 incubated with $5.5 \mathrm{mM}(\mathrm{B})$ and $30 \mathrm{mM}(\mathrm{C})$ glucose for $60 \mathrm{~min}$, respectively. $* P<0.05$, $* * P<0.01$, and $* * * P<$ 4030.001 vs model. Data represent the average of three independent experiments, each performed in duplicate.

404 Fig. 3. Effects of flavonoid 1-6 and $\mathrm{NaVO}_{4}$ on insulin signaling. (A) Akt, GSK3 $\beta$, and PTP-1B phosphorylation status was determined via western blotting. Relative ratio of p-Akt (B), p-GSK3 $\beta$ (C), and PTP-1B (D). Data are expressed as the means $\pm \mathrm{SD}(\mathrm{n}=3)$. $^{* *} P<0.01$ and ${ }^{* * *} P<0.001$ vs control.

407 Fig. 4. Effects on blood glucose levels following administration of flavonoid 2 and 5 in diabetic mice. Healthy mice were treated with vehicle, and type 2 diabetes (T2D) mice were treated with vehicle, flavonoids $\mathbf{2}, \mathbf{5}$, and acarbose for 4 weeks. Fasting blood glucose concentrations (A) and corresponding AUC (B). Effects on maltose and glucose tolerance after administration of flavonoid $\mathbf{2}$ and $\mathbf{5}$ in diabetic mice. (C) Oral glucose tolerance test (OGTT), (D) AUC in OGTT, (E) Oral maltose tolerance test (OMTT), and (F) AUC in OMTT. Data are expressed as the means $\pm \mathrm{SD}(\mathrm{n}=10) .{ }^{*} P<0.05$ and ${ }^{* *} P<0.01$ vs the T2D model. 
416 Chemical components identified from the extract of $C$. morifolium flower.

\begin{tabular}{llllll}
\hline Peak No. & $t_{\mathrm{R}}(\mathrm{min})$ & $\begin{array}{l}{[\mathrm{M}+\mathrm{Na}]^{+} /[\mathrm{M}-\mathrm{H}]^{-}} \\
(\mathrm{m} / \mathrm{z})\end{array}$ & $\begin{array}{l}\text { Predicted values } \\
(\mathrm{m} / \mathrm{z})\end{array}$ & $\begin{array}{l}\text { fragments } \\
(\mathrm{m} / \mathrm{z})\end{array}$ & \begin{tabular}{l} 
Identification \\
\hline 1
\end{tabular} \\
& 35.83 & $485.1047 / 461.1079$ & $485.1054 / 461.1089$ & $\begin{array}{l}217.0383,418.7810,475.3239 \\
/ 130.9476,285.0398\end{array}$ & Diosmetin 7-glucoside \\
& & & & $1130.9468,255.2341,285.0399$ & Diosmin \\
2 & 34.65 & $/ 607.1607$ & $/ 607.1668$ & $217.0446,324.0552,419.2826 /$ & Diosmetin \\
3 & 53.63 & $323.0518 /$ & $323.0526 /$ & $310.0385,418.7813 /$ & Luteolin \\
4 & 47.61 & $309.0356 /$ & $309.0370 /$ & $217.0385,301.1409,475.8242 /$ & Apigenin \\
5 & 52.55 & $293.0406 /$ & $293.0420 /$ & $217.0368,418.7820 /$ & Acacetin \\
\hline
\end{tabular}

417

\section{Table 2}

419 Human PTP-1B inhibition of flavonoids 1-6.

\begin{tabular}{lllll}
\hline \multirow{2}{*}{ No. } & Name & \multicolumn{3}{c}{ Inhibition (\%) ${ }^{\mathrm{a}}$} \\
\cline { 3 - 5 } & & $20 \mu \mathrm{M}$ & $5 \mu \mathrm{M}$ & $1 \mu \mathrm{M}$ \\
\hline $\mathbf{1}$ & Diosmetin 7-glucoside & $29.79 \pm 1.03$ & $23.36 \pm 0.52$ & $27.74 \pm 2.10$ \\
$\mathbf{2}$ & Diosmin & $30.53 \pm 3.63$ & $32.82 \pm 2.84$ & $36.26 \pm 1.62$ \\
$\mathbf{3}$ & Diosmetin & $28.27 \pm 3.71$ & $27.10 \pm 2.89$ & $22.81 \pm 2.07$ \\
$\mathbf{4}$ & Luteolin & $39.92 \pm 1.62$ & $40.75 \pm 2.84$ & $19.80 \pm 2.18$ \\
$\mathbf{5}$ & Apigenin & $39.17 \pm 0.87$ & $20.23 \pm 0.10$ & $29.77 \pm 1.48$ \\
$\mathbf{6}$ & Acacetin & $32.05 \pm 2.85$ & $36.26 \pm 2.70$ & $38.17 \pm 1.62$ \\
& Sodium orthovanadate & & \\
\end{tabular}

${ }^{\mathrm{a}}$ Results represent the average of three independent experiments, each performed in duplicate. ${ }^{\mathrm{b}}$ Reference compound.

\section{Table 3}

$424 \quad \alpha$-Glucosidase inhibition of flavonoids $\mathbf{1 - 6}$.

\begin{tabular}{lll}
\hline No. & Name & $\mathrm{IC}_{50}(\mu \mathrm{M})^{\mathrm{a}}$ \\
\hline $\mathbf{1}$ & Diosmetin 7-glucoside & $>100$ \\
$\mathbf{2}$ & Diosmin & $>100$ \\
$\mathbf{3}$ & Diosmetin & 46.45 \\
$\mathbf{4}$ & Luteolin & 16.65 \\
$\mathbf{5}$ & Apigenin & 9.04 \\
$\mathbf{6}$ & Acacetin $^{\mathrm{ac}}$ & $>100$ \\
& Acarbose $^{\mathrm{b}}$ & 51.30
\end{tabular}

$425{ }^{a}$ Results represent the average of three independent experiments, each performed in duplicate. ${ }^{b}$ Reference 426 compound.

\section{Table 4}

429 TC and TG levels of mouse groups.

\begin{tabular}{|c|c|c|c|}
\hline Group & Dosage (mg/kg) & $\mathrm{TG}(\mathrm{mM})^{\mathrm{a}}$ & $\mathrm{TC}(\mathrm{mM})^{\mathrm{a}}$ \\
\hline Healthy & & $1.55 \pm 0.24$ & $5.23 \pm 0.17$ \\
\hline T2D model & & $3.08 \pm 0.84$ & $9.75 \pm 0.11$ \\
\hline
\end{tabular}




\begin{tabular}{llll} 
Acarbose & 50 & $3.02 \pm 0.79$ & $9.61 \pm 0.27$ \\
$\mathbf{2}$ & 50 & $2.04 \pm 0.36^{*}$ & $9.18 \pm 0.20$ \\
$\mathbf{2}$ & 100 & $2.24 \pm 0.38^{*}$ & $8.94 \pm 0.18^{*}$ \\
$\mathbf{5}$ & 50 & $3.13 \pm 0.35$ & $7.60 \pm 0.64^{* *}$ \\
$\mathbf{5}$ & 100 & $3.06 \pm 0.26$ & $8.22 \pm 0.38^{* *}$ \\
\hline
\end{tabular}

430

${ }^{a}$ Data are expressed as the means \pm SEM $(n=10) .{ }^{* *} P<0.01,{ }^{*} P<0.05$ vs the type 2 diabetes (T2D) model. 
A

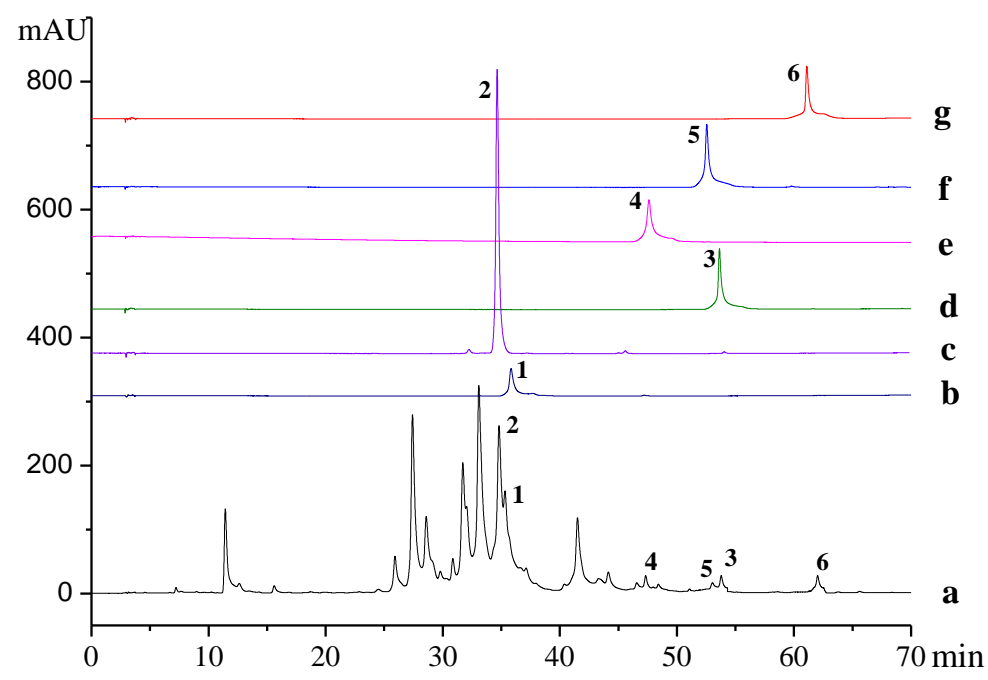

436<smiles>[R10]Oc1ccc(-c2cc(=O)c3c(O)cc([R20])cc3o2)cc1[R]</smiles>
$2 \mathrm{R}^{1}=\mathrm{CH}_{3}, \mathrm{R}^{2}=\mathrm{OH}, \mathrm{R}^{3}=\mathrm{HO}$ $3 \mathrm{R}^{1}=\mathrm{CH}_{3}, \mathrm{R}^{2}=\mathrm{OH}, \mathrm{R}^{3}=\mathrm{H}$ $4 \mathrm{R}^{1}=\mathrm{R}^{3}=\mathrm{H}, \mathrm{R}^{2}=\mathrm{OH}$ $5 \mathrm{R}^{1}=\mathrm{R}^{2}=\mathrm{R}^{3}=\mathrm{H}$ Diosmetin $6 \mathrm{R}^{1}=\mathrm{CH}_{3}, \mathrm{R}^{2}=\mathrm{R}^{3}=\mathrm{H}$ 


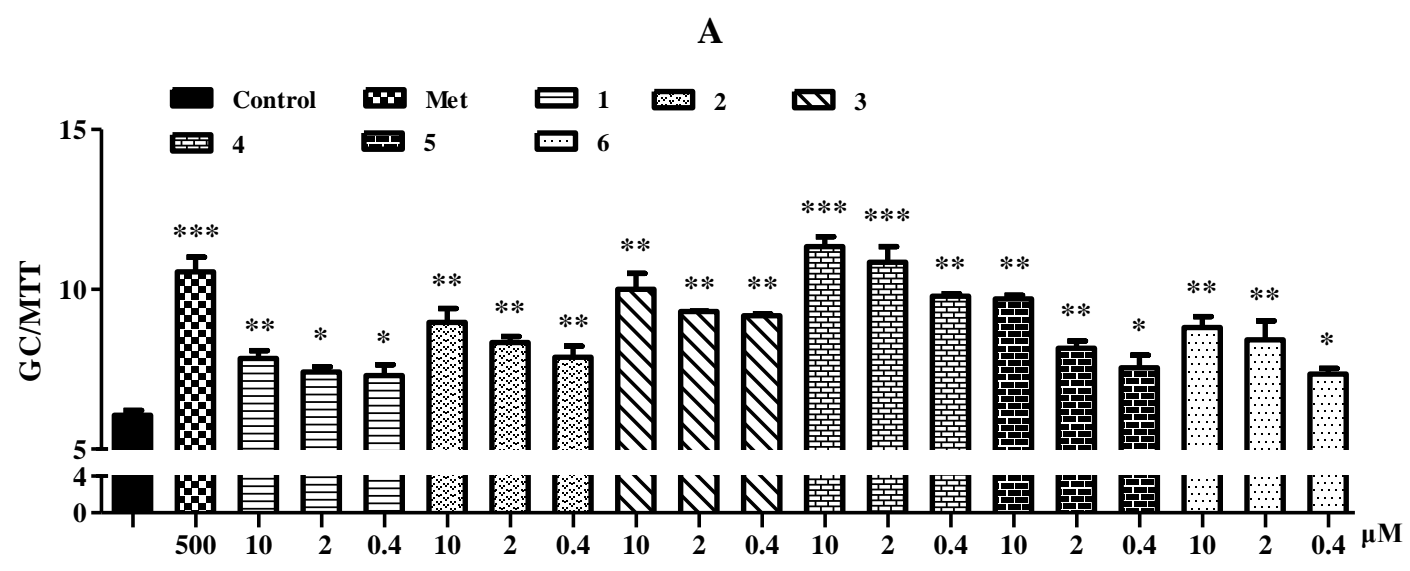

445

446

447

448

449

450

451

452

453

454

455

456

457

458

459

460

461

462

463

464

465

466
B
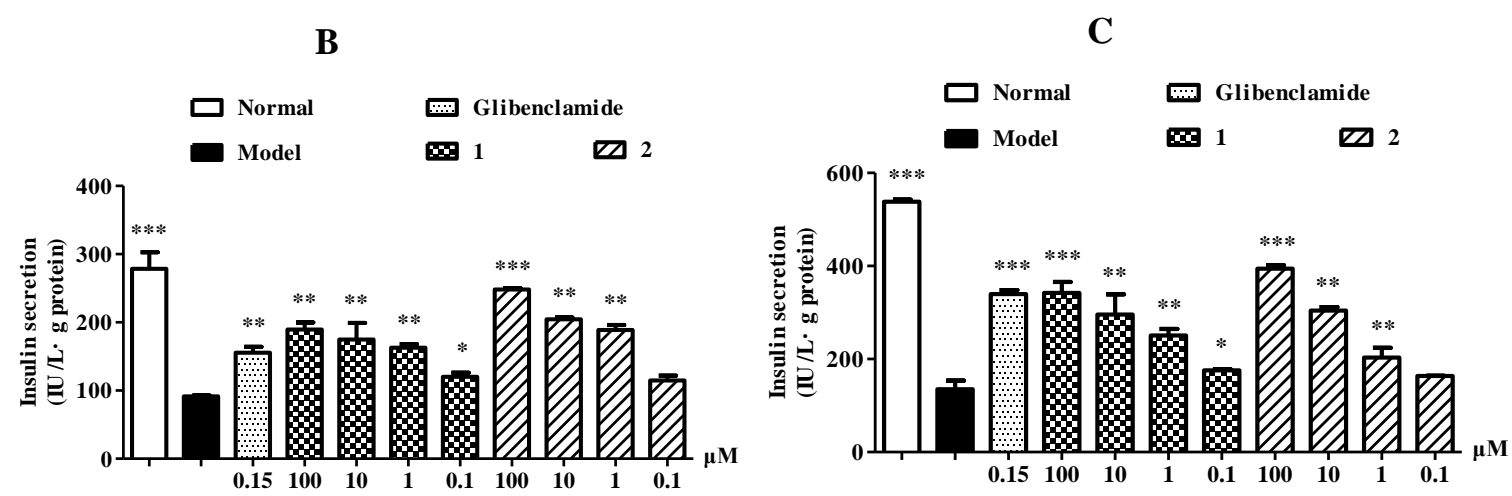


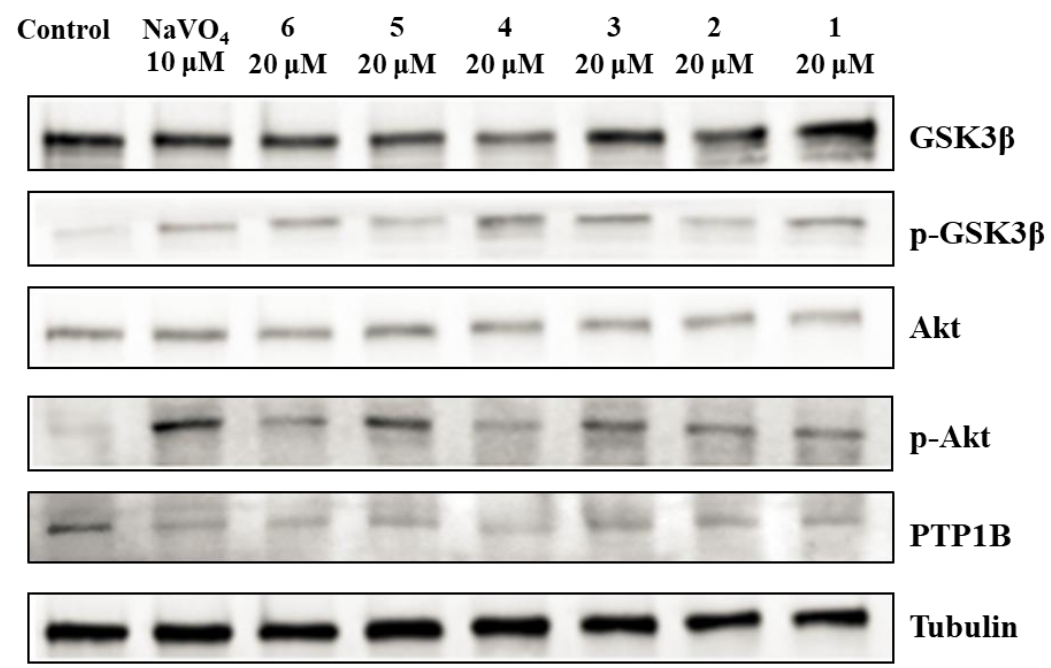

B

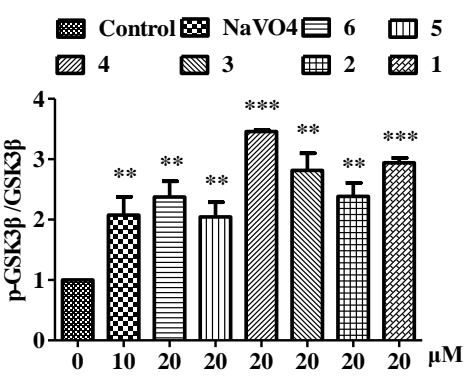

C

Control $\mathrm{B}$ NaVO4曰 6 四 5 西 4 四 2 四

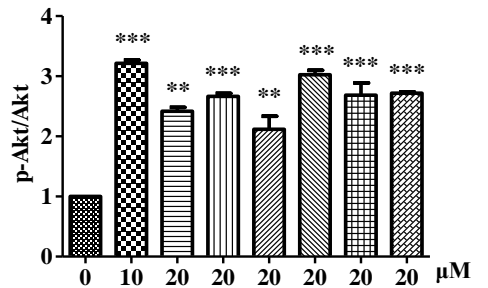

D

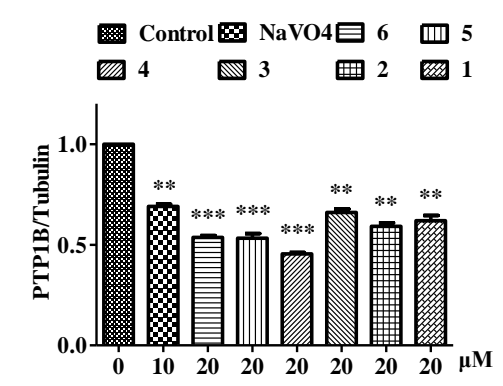


487

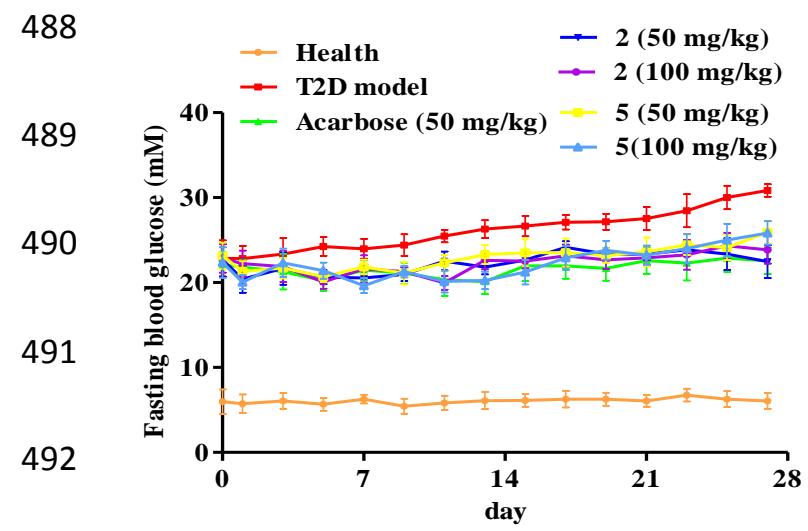

493

494

495

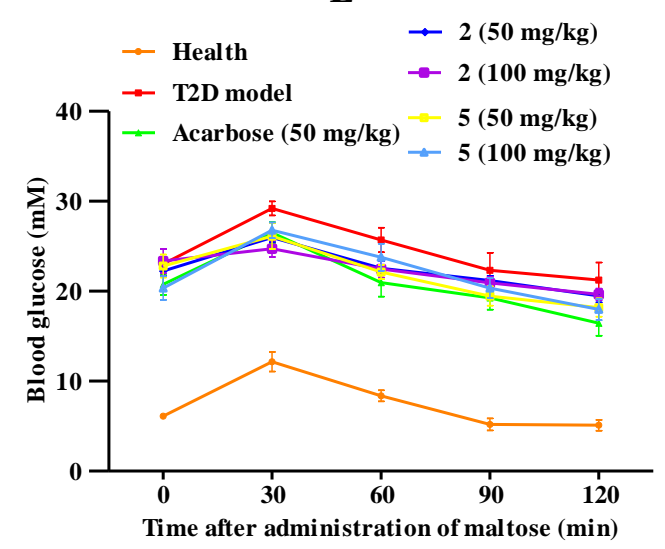

B

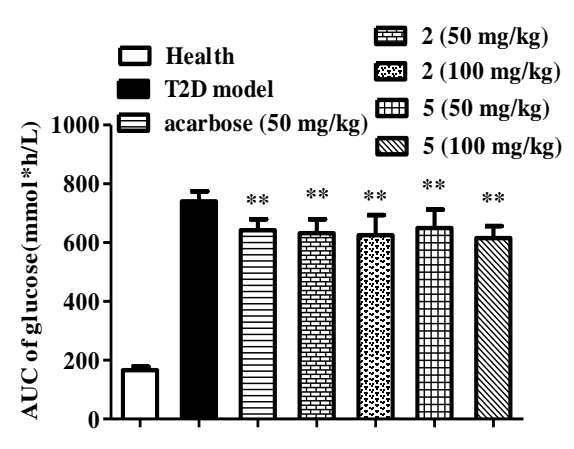

D

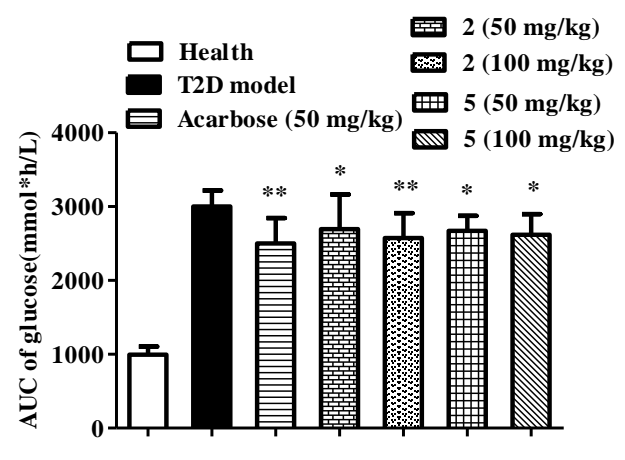

F

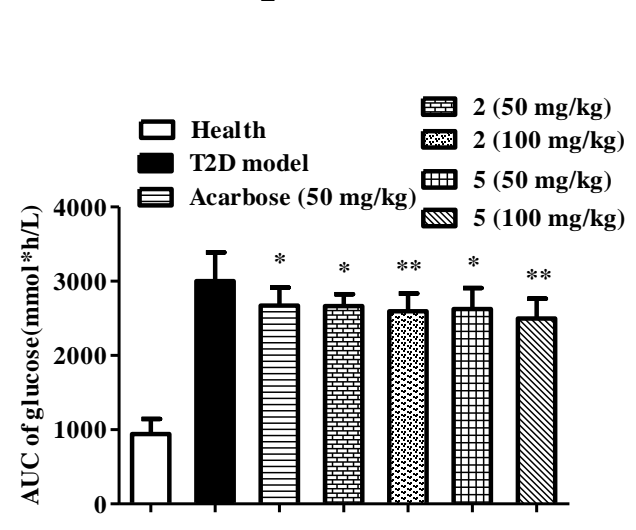

